\title{
SCHOOL-BASED IN-SERVICE TEACHER TRAINING IN LITERACY
}

\author{
Abha Gupta, \& Guang Lea Lee \\ Department of Teaching and Learning/Old Dominion University (USA)
}

\begin{abstract}
The current study is based on a year-long collaboration between a school and a university regarding professional development training of teachers who taught $4^{\text {th }}$ and $5^{\text {th }}$ grade students in an elementary school in the USA. The three-pronged focus of the study was on teacher knowledge, pedagogy and student achievement. We examined how the teacher capacity building affected the performance of underachieving students in Math and Literacy. Students' disaggregated test data was used to meet differential needs of students. Underachieving students were targeted with specific strategies, projects, problems solving stories, self-reflection, higher level thinking questions, to motivate students. Participating students' performance was measured with respect to literacy achievement. Quantitative and qualitative measures were used for data collection purposes. Students showed progress over previous years in reading scores. The results were positive and showed progress over previous years with respect to student achievement. Overall, 93 percent of students passed the writing test. In addition, the benchmark data revealed improvements during the year in reading, editing and writing scores for both $4^{\text {th }}$ and $5^{\text {th }}$ grade students. For three of the four pre and post-test comparisons, the gain in scores was statistically significant.
\end{abstract}

Keywords: Professional development training, site-based teacher training, literacy training, teacher capacity building in knowledge, pedagogy and student-achievement.

\section{Introduction}

Current standards for students' learning have been developed by the state over the past two decades and are inclusive of both content and practice standards, called Standards of Learning (SOL https://www.doe.virginia.gov/testing/sol/standards_docs/). The idea behind the standards is to ensure that all students receive high quality education. The standards are defined for each subject and each grade. The standards set the goals and annual tests are administered at the end of the year to gauge whether students meet those goals. This puts tremendous pressure on schools to have their students pass the SOLs. This pressure gets trickled down to teachers and, in turn, to the students. All schools are required to publish the results of their SOLs in the form of a "Report card". Funding for the schools is based on the report card, thus high stakes are involved in testing. To support educators in their implementation of these standards, schools provide ongoing training workshops for the teachers. As the expectations for instructional practice have been raised, there is a need for more focused professional development in which teachers develop knowledge and pedagogical skills to support the implementation of these practices in the classroom. Effective professional development is fundamental for teachers to enhance their knowledge, pedagogies, and conducting regular needs assessments to collect data which guides professional learning is crucial (Darling-Hammond, et al., 2017).

Professional development refers to teachers developing and improving their skills to better meet the needs of their students. Characteristics of effective professional development have been identified from the literature (Desimone, 2009; Rotermund, S., DeRoche, J., \& Ottem, R. (2017) and widely endorsed by the field (e.g., Lindmeier et al., 2020; Main \& Pendergast, 2015; Richardson, Miller, $\&$ Reinhardt, 2019). The need for professional development has gained increasing momentum in the current educational practices. Various research studies have highlighted the importance of providing ongoing training of in-service teachers to improve teacher quality (Day, 2002; Niemi, 2015).

Darling-Hammond et al. (2017) conceptualise teacher professional learning "as a product of both externally provided and job-embedded activities that have the potential to increase teachers' knowledge and bring about change in their instructional practice in ways that support student learning". Ajibade \& Bertram (2020) describe the perceptions of selected teachers regarding professional learning and development experiences. In a study to build teachers' capacity to integrate science and math content, Aguirre-Munoz et al. (2021) found that the combination of content knowledge and teacher feedback should be targets of extended professional learning. 


\section{Design}

The mixed method evaluation design used both qualitative and quantitative data to examine participant perceptions and experiences, methods of instruction, and student achievement. To that end, we relied on various data sources to address the research questions outlined above. These sources included teacher questionnaires, teacher grades in the course, classroom observations, and student achievement scores related to reading. The study analyzed data from the teacher participants, classroom observations, and analysis of student achievement data. Descriptive qualitative classroom observations were conducted in all $4^{\text {th }}$ and $5^{\text {th }}$ grade classrooms. The items on the questionnaires and observation instruments were designed to reflect the focus of the study. Student achievement data consisted of scores related to reading achievement from the Standards of Learning (SOL) and Benchmark tests.

\section{Objectives}

The purpose of the study was to enhance teacher knowledge, develop pedagogical skills further and improve student achievement. To achieve this purpose, three research questions guided the current study:

1. How well did teachers master the content \& skills in the professional development activities?

2. To what extent were the content \& skills covered implemented in the $4^{\text {th }}$ and $5^{\text {th }}$ grade classrooms?

3. How did $4^{\text {th }}$ and $5^{\text {th }}$ grade students perform on measures related to reading achievement?

\subsection{Methods}

The school that participated in the study was a Title 1 school with nearly 800 students enrolled in grades preK-five. As many as $98 \%$ of the students were African American and $88 \%$ received free or reduced-price lunch (a determining factor toward Title 1 eligibility), which entitled the school to be a Title 1 school. Title 1 is the largest federally funded educational program in the United States of America. The program provides supplemental funds to school districts to assist schools with the highest student concentrations of poverty to meet school educational goals. Based on the state's Standards of Learning (SOL) test scores, the school had been accredited with warning for the previous two years. Schools with this rating receive extra help to improve their standing by developing a two-year improvement plan with the assistance of local agencies. In order to be fully accredited, an average of $70 \%$ of the students enrolled in the school must pass the SOL tests in each subject area at each grade level. Table 1 shows the SOL scores from 3rd and 5th grade level and subject area since SOLs are tested at these two grade levels. An examination of school's scores show that the criterion was not met for $5^{\text {th }}$ grade students in science. In contrast, ninety percent of $3^{\text {rd }}$ grade students received passing scores in science. The criterion was met in all other subjects for both grade levels. In general, the results demonstrate a steady increase in scores by year. There were 23 teachers who participated in the study.

Table 1. Percentage of Students by Grade Level, Subject Area, and Year who Passed SOL Tests at the local school Compared to State Averages

\begin{tabular}{|l|l|l|l|l|l|l|}
\hline Grade/ Subject & Yr1 @ school & State Avg & Yr2 @school & State Avg & Yr3@school & State Avg \\
\hline Grade 4 & & & & & & \\
\hline English & 61 & 72 & 64 & 85 & 70 & 77 \\
\hline Math & 71 & 83 & 34 & 78 & 85 & $\mathbf{8 8}$ \\
\hline History & 74 & 82 & 78 & 87 & 79 & 89 \\
\hline Science & 75 & 82 & 67 & 84 & 90 & 89 \\
\hline Grade 5 & & & & & & \\
\hline English & 68 & 83 & 64 & 85 & 70 & 85 \\
\hline Math & 47 & 74 & 34 & 78 & 70 & 81 \\
\hline History & 65 & 79 & 78 & 87 & 75 & 85 \\
\hline Science & 43 & 80 & 67 & 84 & 40 & 81 \\
\hline
\end{tabular}

\subsection{Intervention}

Nine teachers from grade $4 \& 5$ participated in the study. Each semester, the university's College of Education faculty members assisted to provide various professional development and other activities for the teachers based on the areas of needs that were identified by the teachers and the school principal. The following section describes the interventions aimed at grades 4 and 5 . The total number of students in grade 4 were 84 and in grade 5, there were 80 students. Most professional development activities remained concentrated in reading and language arts.

Throughout the academic year, professors met regularly with the teachers, conducted classroom visits, and provided materials. Over the course of the research project, the support provided moved from 
formal classes and workshop sessions to more informal one-on-one assistance, advice, and modeling. One of the most important things that we learned was the importance of collaboration. University faculty served as a coach or facilitator rather than as an "expert" providing direct instruction through lectures. Decisions were made collaboratively. The topics or strategies emphasized during professional development were based on an informal survey of the teachers' and administrators' needs and requests and aligned with the research objectives and in the areas of reading, math, and student behavior or discipline.

Criteria used for determining effectiveness were objective, and included student participation and achievement. There was concentrated focus on using higher order questioning strategies to challenge students to think more critically. Teachers concentrated on motivational techniques and ways to promote student accountability. Finally, as a final step in the recursive process, student reflection was guided by more challenging questions such as what they learned and critiques of the authors and readings.

In mathematics, the faculty member worked closely with the schools' lead math teacher in the use of test data to guide instructional decisions. Together, they disaggregated the data to tailor instruction to meet individual needs. The program, "Math Buddies", facilitated this effort because it began simply and progressed to different levels depending on individual student progress. Other strategies designed to actively engage students included the use of manipulatives, calculators, and computer applications.

We used projects, problem solving stories, and library research to actively engage and motivate students. Among students exhibiting discipline or behavioral problems, we contacted other adults in the community to enlist them in providing support and discussed how appropriate behaviors might be reinforced. Faculty members visited the parents in their homes, went to their children's little league games to talk to their coaches, and attended their churches to speak to their pastors or Sunday school teachers.

Teacher Questionnaire: The questionnaire was administered to the nine $4^{\text {th }}$ and $5^{\text {th }}$ grade teachers at the end of the school year. The questionnaire contained both a quantitative rating scale and open-ended items. The rating scale items corresponded to the content covered in the course as well as the topics or strategies covered in the professional development workshops.

\section{Results \& discussion}

Among $4^{\text {th }}$ graders statistically significant improvements were found on both reading and editing scores. There was a significant increase on the average percentage of points obtained when comparing pre- and post-test scores in reading $(\mathrm{t}(1,83)=5.44, \mathrm{p}<.001)$. Students achieved an average of 64.73 percent of the points correct on the pretest and an average of 74.97 percent on the post-test. This represents an impressive increase of over 10 percentage points. Similarly, we found a significant increase in $4^{\text {th }}$ graders editing scores $(\mathrm{t}(1,83)=4.23, \mathrm{p}=.001$. Editing scores improved from a mean of 58.05 to 67.35 , reflecting a substantial increase of nearly 10 points. Fourth graders scored well on these tests, and their scores are improving.

Turning to the performance of $5^{\text {th }}$ graders on the Benchmark tests, we found improvements in both reading and writing scores, but only the change in reading scores was statistically significant $(\mathrm{t}(1,79)=3.21, \mathrm{p}=.02)$. Reading scores improved from a mean percentage of 65.27 to 72.70 . Although the mean difference in writing scores did not reach statistical significance, it did approach this criterion $(p=.10)$, and writing scores did improve from pre to post testing. The average pretest score was 59.48 percent and the average post-test score was 63.39 percent. In both areas these scores reflect improvement and bode well for the actual SOL results presented in the next section.

Table 2. Percentage of $5^{\text {th }}$ Grade SOL English Scores by Category and Proficiency Level.

\begin{tabular}{|l|l|l|}
\hline Category & Proficient & Not Proficient \\
\hline Use word analysis strategies & 66 & 34 \\
\hline $\begin{array}{l}\text { Understand a variety of resource } \\
\text { materials }\end{array}$ & 71 & 29 \\
\hline Understand elements of literature & 74 & 26 \\
\hline
\end{tabular}

In response to first research question, according to the teachers themselves the content and skills were very well mastered. This is evidenced by the consistently high mean scores obtained from the rating scale items pertaining to mastery on the questionnaires. This trend was true across the categories of reading, math, classroom management, and more general strategies. Some exceptions to the pattern of high ratings were the relatively lower ratings found on parental and community involvement, the use of software, and student self-reflection or questioning. However, teachers' confidence in their knowledge of the strategies does not always translate into their frequent use in the classroom.

Teachers own ratings of the frequency with which they used the targeted strategies provided indirect evidence of classroom implementation. High mean ratings were obtained on the use of strategies in the areas of reading, math, and classroom management. In these areas, we found teachers used problem 
solving stories, library research for stories, and parental and community involvement less frequently than the other strategies. Overall, the mean ratings in the general strategies' category tended to a bit lower. Teachers reported less use of technology, literacy across the curriculum, student self-reflection, and a focus on cultural or diversity issues. In the area of reading strategies, we most frequently observed the use of webbing and graphic organizers. Student self-reflection, cooperative learning, and a focus on higher-level thinking were among the most frequently used general strategies. Our own observations, pointing to more frequent use of student reflection, appear to contradict teachers' perceptions on how frequently they employed this strategy.

The third and final question was, "How did $4^{\text {th }}$ and $5^{\text {th }}$ grade students perform on measures related to reading achievement?" The results were positive and showed progress over previous years. This was the first year that $5^{\text {th }}$ grade scores in English reached the state benchmark of a 70 percent passing rate. The $5^{\text {th }}$ grade writing scores were even more impressive. Overall, 93 percent of these students passed the writing test.

\section{Conclusions \& limitations}

While the study provided potentially useful findings regarding content-focused professional development, there are some recommendations that are made and limitations that were observed. First, we did not observe or hear reference to parental involvement activities. Increased parental involvement may promote better student conduct, motivation, and academic engagement among students. Our findings suggest that the level of parental involvement could be increased. Teachers rated the item on parental and community involvement lower than other items under classroom management. Research in the real world of schools often precludes the control of variables to isolate cause-and-effect inferences. In particular, because of the simultaneous implementation of several other programs and interventions within the school, it is impossible to establish a causal link between the activities addressed by the intervention and the academic achievement by the students. Finally, our study relied heavily on self-reporting by the teachers. While the teachers themselves are largely responsible for carrying out any educational reforms, and their feedback is crucial, self-reported data may be biased.

\section{References}

Aguirre-Munoz, Z., Yeter, Ibrahim H., S. Loria Garro, Elias, Koca, Faith. 2021. Building Teachers' Capacity to Integrate Science and Math Content: Implications for Professional Development and Learning. Journal of Science Teacher Education, 32(1) 62-84.

Ajibade, B. A., Bertram, C. 2020. How district teacher development centres support teachers' learning: case studies in Kwazulu-Natal, South Africa. Perspectives in Education 38(2), 103-117.

Cunningham, J. (1982). Generating interactions between schemata and text. In J. A. Niles \& L. A. Harris (Eds.), New inquiries in reading research and instruction (pp. 42-47). Washington, DC: National Reading Conference

Darling-Hammond, L., Hyler, M.E. \& Gardner, M. (2017). Effective teacher professional development. Palo Alto, CA: Learning Policy Institute. Retrieved June 2, 2021, from: https://learningpolicyinstitute.org/sites/default/files/product-files/Effective_Teacher_Professional_ Development_REPORT.pdf

Day, C. (2002). Schools as learning communities: Building capacity through network learning. Education, 30(3), 19-22.

Desimone, L. M. (2009). Improving impact studies of teachers' professional development: Toward better conceptualizations and measures. Educational Researcher, 38(3), 181-199.

Lindmeier, A., Seemann, S., Kuratli-Geeler, S., Wullschleger, A., Dunekacke, S., Leuchter, M., Heinze, A. (2020). Modeling early childhood teachers' mathematics-specific professional competence and its differential growth through professional development - an aspect of structural validity. Research in Mathematics Education, 22(2), 1-20.

Niemi, H. (2015). Teacher professional development in Finland: Towards a more holistic approach. Psychology, Society, \& Education, 7(3), 279-294.

Richardson, K., Miller, S., \& Reinhardt, J. (2019). Professional development as an ongoing partnership: The sum is greater than its parts. School-University Partnerships Furthering the Education Profession: Partnerships in Action, 12 (1), 45-50.

Rotermund, S., DeRoche, J., \& Ottem, R. (2017). Teachers professional development by selected teacher and school characteristics: 2011-2012. [Stats in brief]. NCES 2017-200. National Center for Educational Statistics. Retrieved June 2, 2021, from: https://nces.ed.gov/pubs2017/2017200.pdf 